\title{
17. Water supply and sanitation in India: Meeting targets and beyond
}

\author{
Sridhar Vedachalam \\ Cornell University, United States
}

Target 7C of the Millennium Development Goals (MDG) calls for halving the proportion of the population (baseline 1990) without sustainable access to safe drinking water and basic sanitation by 2015 (United Nations (UN) 2000). A large developing country like India is critical to meeting this target. Even though the MDGs set out to measure and reduce the population without sustainable access to safe water and sanitation, difficulties have been encountered in measuring 'safe' and 'sustainable', which have led to a revision of the target to achieving access to improved sources of water and sanitation (Zetland 2008). It has been argued that the revised goals grossly overestimate the access to safe water and sanitation (Bain et al. 2012; Satterthwaite 2009).

Table 1: Population (per cent) of India with access to improved sources of water

\begin{tabular}{|l|l|l|l|}
\hline Year & Urban & Rural & Total \\
\hline 1990 & 88 & 63 & 69 \\
\hline 1995 & 90 & 70 & 75 \\
\hline 2000 & 93 & 77 & 81 \\
\hline 2005 & 95 & 83 & 86 \\
\hline 2010 & 97 & 90 & 92 \\
\hline
\end{tabular}

Source: World Health Organization (WHO) and United Nations Children's Fund (UNICEF) 2012a.

Table 1 shows the distribution of India's population with access to an improved drinking water source. By 2010, 92 per cent of the population had access to an improved source of water, which brought down the proportion of the population without such access from 31 per cent in 1990 to eight per cent in 2010 (WHO/ UNICEF 2012a). If Target 7C of the MDG (improved water access) were to be applied on a country-level basis, India has already surpassed the target well before 2015 . 
Global Water: Issues and Insights

Table 2: Population (in percent) of India with access to improved sources of sanitation, and no sanitation

\begin{tabular}{|l|l|l|l|l|l|l|}
\hline \multirow{2}{*}{ Year } & \multicolumn{3}{|c|}{ Improved } & \multicolumn{3}{c|}{ No sanitation } \\
\cline { 2 - 7 } & Urban & Rural & Total & Urban & Rural & Total \\
\hline 1990 & 51 & 7 & 18 & 28 & 91 & 75 \\
\hline 1995 & 53 & 10 & 21 & 25 & 86 & 70 \\
\hline 2000 & 55 & 14 & 25 & 22 & 79 & 63 \\
\hline 2005 & 56 & 19 & 30 & 18 & 73 & 57 \\
\hline 2010 & 58 & 23 & 34 & 14 & 67 & 51 \\
\hline
\end{tabular}

Source: WHO/UNICEF 2012b. The proportions of the population with access to improved sources and no sanitation do not add up to 100 percent. The remaining population has access to unimproved sources.

It is a somewhat different story, however, on the sanitation front. Table 2 shows the proportion of the population with access to an improved source of sanitation, and those that lack any source of sanitation and have to use open defecation. Though the proportion of the population with access to improved sanitation nearly doubled in the last 20 years, a majority of the population still does not have access to any sanitation and has to resort to open defecation (WHO/UNICEF 2012b). The five states of Chhattisgarh, Madhya Pradesh, Bihar, Jharkhand and Odisha - largely rural and located in the central and eastern parts of the country - have less than 30 per cent access to a sanitation source (International Institute for Population Sciences and Macro International (IIPS) 2007). It appears that India is likely to miss Target 7C of the MDG (improved sanitation access), and any hope of achieving the target by 2015 rests on the progress made in these five large states.

Access to water and sanitation also involves issues of gender and caste. In 2005, only half the population had access to water on the household premises, and 12 per cent spend 30 minutes or longer daily to get water for the household (IIPS 2007). Of the households that don't get water on premises, adult females are responsible for fetching water in 81 per cent of the families. Even among children below 15 years of age, girls are four times more likely than boys to be responsible for collecting water (IIPS 2007). Beyond gender, Indian society also has an uncomfortable history with caste discrimination that is relevant to sanitation access: lower castes have been traditionally entrusted with occupations such as collecting human/livestock waste.

These underlying traditions show up in the data as well. The states with the highest rates of access to sanitation (except the capital region of Delhi) are the eight north-eastern states and the southern state of Kerala, all of which are known for an egalitarian society (Milner 2009; Subramanyam and Subramaniam 2011). Additional analysis of the sanitation data by income quintiles reveals 
that the poorest 40 per cent in India have hardly benefited from improvements in sanitation. The poorest quintile is 47 times more likely than their richest counterpart to practice open defecation, a disparity three times greater than that observed in Africa (Brocklehorst 2010).

Table 3: Status of water supply and wastewater treatment in the six largest cities of India

\begin{tabular}{|l|l|l|l|l|l|l|}
\hline \multirow{3}{*}{ City } & \multicolumn{4}{|l|}{ Water supply } & Wastewater \\
\cline { 2 - 7 } & $\begin{array}{l}\text { Capacity } \\
\text { (MLD) }\end{array}$ & $\begin{array}{l}\text { Hours } \\
\text { per day }\end{array}$ & $\begin{array}{l}\text { Consumption } \\
(\text { LPCD) }\end{array}$ & $\begin{array}{l}\text { Unaccounted } \\
(\%)\end{array}$ & $\begin{array}{l}\text { Generated } \\
\text { (MLD) }\end{array}$ & $\begin{array}{l}\text { Treatment } \\
\text { capacity } \\
\text { (MLD) }\end{array}$ \\
\hline Bangalore & 965 & 4 & & $34-44$ & 772 & \\
\hline Chennai & 198 & 4 & & 20 & 158 & 264 \\
\hline Delhi & 4346 & 4 & 78 & 26 & 3800 & 2330 \\
\hline Hyderabad & 578 & $0.5-4$ & 96 & 33 & 462 & 593 \\
\hline Kolkata & 1625 & 9 & 116 & $30-40$ & 706 & 172 \\
\hline Mumbai & 3000 & 5 & 90 & 18 & 2400 & 2130 \\
\hline
\end{tabular}

Source: McKenzie and Ray 2009; Shaban and Sharma 2007; Central Pollution Control Board 2009.

Although urban areas of the country fare better than their rural counterparts on water and sanitation access, a larger and denser population, coupled with dwindling natural sources of freshwater pose unique challenges to large cities, such as Bangalore, Mumbai and New Delhi. Table 3 shows the status of water and wastewater infrastructure in the six largest cities in India. Though the major cities reported an increase in the service coverage between 1991 and 1997 (Ruet et al. 2002), the availability of water supply ranges from four hours or less per day in Delhi, Bangalore and Hyderabad to nine hours in Kolkata; and 18 per cent (Mumbai) to 50 per cent (Kolkata) of the urban water is unaccounted for (McKenzie and Ray 2009). A household study conducted in seven cities in India found the average per capita consumption of water to be 92 litres per capita per day (LPCD), below the World Health Organization (WHO) guideline of 100 LPCD for optimal access (Shaban and Sharma 2007). Further analysis of the data by socio-economic quintiles shows that water consumption increases with a rise in socio-economic status, although the inter-quintile differences are not significant. The near-uniform water consumption across different income groups is largely a result of supply constraints and is not impacted by varying economic abilities (Shaban and Sharma 2007).

These numbers raise doubts about whether access to improved water sources translates to regular availability of safe water. Residents in several Indian cities augment their piped supplies with private wells and other informal methods, such as private tankers (Srinivasan et al. 2010). The use of groundwater for 
residential as well agricultural consumption is driving down water tables in many parts of the country, especially the agricultural bread-baskets of Punjab and Haryana (Rodell et al. 2009). Continued groundwater depletion can result in an inability to meet residential needs, reduced agricultural productivity and increased conflict over water rights.

Additionally, the lack of wastewater treatment capacity in cities like Delhi and Kolkata (Central Pollution Control Board 2009) threatens public health and the safety of already-scarce freshwater resources. A discussion on water security is incomplete without planning for adequate infrastructure for wastewater treatment. Not only does it allow for better management of available water resources, treated wastewater can be an additional source of freshwater in waterdeficient regions (Vedachalam 2012).

Even though India has reported tremendous progress towards achieving the MDGs for access to water, the revised targets do not necessarily mean continuous and safe access to water, not to mention economically affordable water. Even large cities that boast higher rates of access are able to guarantee little water for a few hours a day, imposing health, economic and social costs on the residents. The Indian economy loses 73 million working days a year due to waterborne diseases, caused by a combination of lack of clean water and inadequate sanitation (DFID 2010). Access to sanitation, even more so than water, is a robust indicator of human development due to the complex role played by social, institutional and cultural factors (Vedachalam 2011). Low rates of access to sanitation underscore lack of action on several fronts, only some of which are due to lack of financial resources. Targeted investments in communities and individuals (Gupta 2012), along with institutions, will allow India to expand and ensure safe access to water and sanitation to all its residents well beyond 2015.

Dr Sridhar Vedachalam is a Postdoctoral Associate at the New York State Water Resources Institute at Cornell University. His research involves analysing water and wastewater infrastructure issues, such as planning, financing, use and regulation. He received his $\mathrm{PhD}$ in environmental science from The Ohio State University. He can be contacted at sv333@cornell.edu.

\section{References}

Bain, R.E.S., Gundry, S.W., Wright, J.A., Yang, H., Pedley, S. and Bartram, J.K., 2012. Accounting for water quality in monitoring access to safe drinkingwater as part of the Millennium Development Goals: lessons from five countries', Bulletin of the World Health Organization, 90:228-35A. 
Brocklehurst, C., 2010. 'Water, sanitation and hygiene - the big picture', United Nations Children's Fund. Available at: http:/www.unicef.org/wash/ index_bigpicture.html.

Central Pollution Control Board, 2009. 'Status of water supply, wastewater generation and treatment in class-I cities and class-II towns of India', Government of India.

Department for International Development (DFID), 2010. 'Access to Safe Water for the Bottom of the Pyramid: Strategies for Disseminating Technology Research Benefits', UK. Available at: http://www.dfid.gov.uk/R4D/PDF/ Outputs/water/Secondary_Research_Report.pdf.

Gupta, S., 2012. 'Woman who risked marriage for sanitation awarded', Times of India, 24 February. Available at: http://articles.timesofindia.indiatimes. com/2012-02-24/bhopal/31094479_1_toilet-tribal-woman-sulabhinternational.

International Institute for Population Sciences and Macro International (IIPS), 2007. 'National family health survey (NFHS-3), 200506: India', volume I, Mumbai.

McKenzie, D. and Ray, I., 2009. 'Urban water supply in India: status, reform options and possible lessons', Water Policy 11:442-60.

Milner, M., 2009. 'Youth culture in a "faraway place"", The Hedgehog Review, Spring:65-73.

Rodell, M., Velicogna, I. and Famiglietti, J.S., 2009. 'Satellite-based estimates of groundwater depletion in India', Nature, 460:999-1002.

Ruet, J., Saravanan, V.S. and Zerah, M-H., 2002. 'The water and sanitation scenario in Indian metropolitan cities: resources and management in Delhi, Calcutta, Chennai, Mumbai', Centre de Sciences Humanes, New Delhi, Occasional Paper.

Satterthwaite, D., 2009. 'The Millennium Development Goals and urban poverty reduction: great expectations and nonsense statistics', Environment \& Urbanization, 15(2):179-90.

Shaban, A. and Sharma, R.N., 2007. 'Water consumption patterns in domestic households in major cities', Economic and Political Weekly 42(23):2190-7.

Srinivasan, V., Gorelick, S.M. and Goulder, L., 2010. 'A hydrologic-economic modeling approach for analysis of urban water supply dynamics in Chennai, India', Water Resources Research 46:W07540. 
Subramanyam, M.A. and Subramaniam, S.V., 2011. 'Research on social inequalities in India', Indian Journal of Medical Research, 133(May):461-3.

United Nations (UN), 2000. 'United Nations Millennium Declaration', United Nations General Assembly, New York, September 18. Available at: http:// www.un.org/millennium/declaration/ares552e.pdf.

Vedachalam, S., 2011. 'WaSH and human development', Aguanomics, blog post 18 May. Available at: http://www.aguanomics.com/2011/05/wash-andhuman-development.html.

— 2012. 'Water supply in Chennai: desalination and missed opportunities' , Economic and Political Weekly 47(23):23-6.

World Health Organization (WHO)/United Nations Children's Fund (UNICEF), 2012a. 'Estimates for the use of improved drinking-water sources: India', Joint Monitoring Programme for Water Supply and Sanitation, World Health Organization \& United Nations Children's Fund, March. Available at: www. wssinfo.org.

— , 2012b, 'Estimates for the use of improved sanitation facilities: India', Joint Monitoring Programme for Water Supply and Sanitation, World Health Organization \& United Nations Children's Fund, March. Available at: http:// www.wssinfo.org.

Zetland, D., 2008. 'The economics of clean water: a guest post', Freakonomics, blog post, 9 September. Available at: http://www.freakonomics.com/2008/09/09/ the-economics-of-clean-water-a-guest-post/. 
This text taken from Global Water: Issues and Insights by R. Quentin Grafton, Paul Wyrwoll, Chris White and David Allendes, published May 2014 by ANU Press, The Australian National University, Canberra, Australia. 